coherent philosophy with which to conceptualise illness and the treatment of ill people.

JAMES MATHERS

\section{Quest for Excellence in Medical Education}

Sir George Pickering, published for Nuffield Provincial Hospital Trust by Oxford University Press, I978. I02pp, £4.50.

Medical Education and Medical
Care, a Scottish - American Sym-
posium, Gordon McLachlan
(Editor), published for Nuffield
Provincial Hospital Trust by Oxford
University Press, I977, 2 I $5 \mathrm{pp}, £ 6.00$.

Sir George's recent death deprived us of one of the major figures in post-war British medicine. One of his outstanding qualities was the balance of his interest and skill in the three separate areas of clinical medicine, research and education. $\mathrm{He}$ combined these interests to an amazing and some would say unique degree, and it is this which makes the prospect of his book fascinating. There have been a large number of pressures on medical education in the last decade. Graduate output has increased. The scientific knowledge required as a background to practice has widened. New schools with new ideas have been formed, and the demands and standards of postgraduate practice have altered. There have been other challenges to expansion, however, most recently the stark economic reality of the enormous expense of medical education compared with other university courses. Medical unemployment could be a reality within a few years. Specialist and high technology medicine has been challenged at all levels, certainly by the renewed interest amongst medical students in general practice. All this should mean that medical educators are thinking hard about their task, and should be questioning the assumptions of their predecessors. Sometimes this seems to be the case, but more often the debate is confined to parochial issues, power struggles, and the defence of the status quo, ancient or modern. Sir George, asked by the Nuffield Provincial Hospital's Trust after the I973 Pembroke Conference to survey medical education in general has avoided all the temptations of narrow thinking and has provided something that was desperately needed, a short and well written piece which asks sharp and perceptive questions, and comes up with concise but deep and well-reasoned answers. Unlike the representatives of more recent reports on medical education, he visited the institutions he concentrates on and saw what they were actually doing, not what they said they were doing. As a piece of work it seems a model of its kind.

What he found is more alarming. Medical students are brighter and keener than ever before, and yet within the schools he often found them bored, felling they were 'data banks' and asked to cram current dogma rather than develop their own minds by using their observations and learning to achieve a synthesis of their own. This runs counter to the clear need of the undergraduate to learn how to learn in order to face a professional life full of changes in emphasis and practice. The idea that a graduating doctor should be immediately able to practise in any field, although implied in the Medical Acts, Sir George exposes for the nonsense it is; but he shows that this still has not led teachers or examiners to respond suitably. Now that postgraduate education is a reality for all branches of medicine, specialist teaching should be given at this point, and yet again he points out how examinations geared to reduce the chance of a badly trained doctor slipping through, and thus keeping up standards in general, are equally discouraging to original thought, literacy and scholarship and provided dogma not education as their pabulum. These and other ideas form challenging reading which should be required for anyone who teaches in medicine at any level.

The stimulation of Sir George's short piece (and why was it not in paperback?) contrasts with the broad and leisurely symposium on the contributions which Scotland and the USA have made to medical education and care, and the problems that these two countries face in common or in contrast. For anyone interested in history this is pleasant and useful reading, but it failed, as perhaps so many symposia fail, to have a cutting edge which helps us to shape the future. Several of the contributors were first rate, but what they had to say seemed to me curiously blunted. I am sure great benefits were derived by those who attended, but I feel the Trust spends its money better for the reader when asking an individual to come up with a definitive statement, based $\overline{\text { on }}$ observation, like Sir George's, ratker than a wide series of the type $\Rightarrow f$ survey that we find in this symposium. Which having been said, \&e should pay tribute to the work t the Trust has done in so my unusual but important and influmtial areas of medical education. May its foresight and generosity contiffue to enlighten us!

ROGER HIGGSS

The End of an Age of Optimis商Medical Science in Retrospegt and Prospect

Colin Dollery

के

Rock Carling Monograph, 'Thise Nuffield Provincial Hospitals Trugt, I 978, $95 \mathrm{pp}, £ 3.75$.

The last decade has witnessed wave of criticism of west medicine and its relationship with science. Two of the most imaginatioe and radical attacks have come from previous Rock Carling Fellowis, Cochrane in 1972 and McKeownon I976. Their monographs have be much debated and have rapidy become medical classics. Dolle has therefore a difficult traditign to follow in reviewing the role $\Rightarrow f$ science in medicine, in part as answer to the critics.

He begins with a useful survey声f the main criticisms which he draws up in the form of a list of charges against medical science. Apart frộn medical conspiracy, he finds thest they each have some substance, but have been greatly exaggerated. Frøin this he concludes that taken over 1 , science has served medicine woll and the acknowledged deficiencies, though not unimportant, are pespheral. It is significant that the ory charge judged unequivocally ofs guilty is medical 'gullibility' in accepting new procedures and drugs, which implies the need for an eve greater application of traditioner scientific method. The types $\delta$ f problem facing medicine are seen basically unchanged and will be bost remedied by more of the same approach, with some additions and modifications to allow for alterg circumstances. The remaining cha ters are mainly concerned with $\mathrm{Q}_{\mathrm{a}}$ more detailed justification and wordeing through of this theme, especially concerning the organisation arrangements for research. 
From a traditional medical perspective, this is a fair and well reasoned analysis, which brings together the different aspects of the debate and shows a willingness to accommodate. But what such an approach fails to confront is the collective significance of the criticisms and their fundamental challenge to the established meaning of science and the role of medicine in society. Biomedical research is certainly capable of developing further sophisticated technology, but how far future medical progress will be judged in these terms is open to doubt.

DAVID A GREAVES

\section{Family Formation 1976}

Karen Dunnell

Office of Population Censuses and Surveys, Social Survey Division: HMSO, 1979, I I 7 pp, £7.50.

It could be argued that this report will not assist general practitioners, obstetricians or gynaecologists in the decisions - sometimes ethical ones - which they take about such fertility-related matters as contraceptive prescribing, termination of pregnancy, sterilisation, etc. In fact it might be seen as detrimental to wise decision-taking, since this is a report of a large-scale survey and therefore has the job of generalising about groups of women, whereas to take decisions about individuals one must particularise, and not stereotype. Yet, it would be a pity if this study were not read by all those interested in placing the family formation behaviour of individual women within a wider societal context. For this is a very clearly written and informative study, providing not only a great deal of descriptive data on the pregnancies, sexual behaviour and contraceptive usage, marriages and separations of a sample of over 6000 British women, but also supplementing this with data which may help one to understand trends and differences in behaviour (such as women's education, paid employment, husbands' employment and job security, views on ideal and intended family size).

Although the study is of interest to those particularly concerned with research on fertility it also has the merit of being written without the assumption that readers already possess a high degree of prior knowledge of the subject, thus making itself available to a much wider audience. The only drawback of such an approach is that the report may fail to hold the attention of those who do have prior knowledge since it frequently provides merely confirmation of already wellestablished trends or explains concepts already understood.

However, there are also new findings to report, some of which are interesting in the fact that they can be compared with the findings of previous studies (for example, the decline in family size ideals since r967), and some in the fact that they break new ground (for example, the information provided on single women and those not legally married but cohabiting). It cannot be blamed for leaving its readers somewhat frustrated by the sense that its findings may now be out of date, for this is bound to be the case with large-scale surveys of changing behaviour.

JANET ASKHAM

Mixed Communications: Problems and Progress in Medical Care: Essays on Current Research

Twelfth Series. Gordon McLachlan (editor). Oxford University Press for Nuffield Provincial Hospitals Trust, I979, I27 pp, £4.50.

Five Years After: A Review of Health Care Research Management

Gordon McLachlan (editor). Oxford University Press for Nuffield Provincial Hospitals Trust, 1978, $85 \mathrm{pp}, £ 2.25$.

Both these books, dealing respectively with the conduct and content of medical care research, come from a charitable organisation which has a deserved reputation for the independent promotion of such worthy matters. The Nuffield Provincial Hospitals Trust has funded medical care research for many years and the results of their patronage have been regularly reported in a series of which 'Mixed Communications' is simply the latest example.

The other publication, 'Five Years After', addresses a policy issue which arouses passionate debate since it concerns the most appropriate means by which governments can finance research in the vast field of health. The topic boiled up in the early seventies with the publication of the Rothschild Report and the subsequent Green and White Papers. The idea was to design a framework which would 'make the best use of science and technology for the needs of the community as a whole'. An unexceptionable aim, one might think. But what incensed the academic community of the day was their reduction to the demeaning role of research pedlars, selling their tinkering skills to the Government who, as the wealthy customer, would only demand or buy specific products. The metaphor was not only resented but has since proved inappropriate and also very hard to implement in practice. As a result of unsatisfactory experiences with this model the whole process is now due for redesigning, which makes this publication highly relevant to a revived debate on the special theme of health service research.

This book makes especially lively reading in the first half where Professor Whitehead unabashedly relates personalities to policies in his historical review. Among the multiple problems which have arisen the key one is the sheer inability of governments or, rather, civil service administrators, to decide what is needed from medical research. The customer, in fact, is uninformed and ignorant and in no position to tell, without special advice or advertisement from the retailers themselves, what constitutes the best medical buy. Most of the book concentrates on the shaky mechanisms set up in England, in the DHSS, to get round these difficulties. It is unfortunate that the much superior Scottish arrangements do not feature here but they were described a year earlier in another Nuffield volume, 'Research in Medicine', by Sir Andrew Watt Kay.

From mixed experiences to mixed communications, we find in the other publication four very different themes, how to improve doctors' skills at talking to patients; the unmet needs of handicapped children and their parents; hospital in-patient costs and, finally, problems arising over participation in managing the health service. Charles Fletcher is eminently reasonable and humane on the matter of patients' right to know about their illness and on ways of ensuring that doctors will do better at this important task in future. Jack Hallas, in the last essay, ranges widely, but with a refreshing 